\title{
A interseccionalidade como base do feminismo negro
}

Halina Macedo Leal ${ }^{1}$

\begin{abstract}
Resumo: A análise de processos de opressão de gênero começa a emergir nas reflexões filosóficas, seja pelo foco no funcionamento do sistema patriarcal ou pelo foco na intersecção do patriarcado com relações de dominação a partir de origens etnicorraciais. Em geral, tais reflexões buscam examinar os fundamentos dos sistemas opressivos e a reação das mulheres a tais sistemas. São localizadas diferentes formas e demandas dos movimentos feministas e os modos como estes procuram, por meio da discussão sobre gênero, fortalecer o papel social e político das mulheres. Neste contexto, o presente artigo visa examinar o lugar do feminismo negro no debate e suas bases de sustentação, tendo em vista as peculiaridades das necessidades das mulheres negras. Estas peculiaridades estão relacionadas à inseparabilidade estrutural entre patriarcado, sexismo, racismo e suas articulações que implicam em múltiplas situações de opressão sofridas por este grupo de mulheres. Em outras palavras, busca-se analisar a centralidade do conceito de interseccionalidade para a compreensão da atuação do feminismo negro nas reflexões filosóficas acerca da condição da mulher negra na sociedade.
\end{abstract}

Palavras-chave: Feminismo Negro - Gênero - Interseccionalidade - Opressão - Raça

\section{The intersectionality as ground of black feminism}

\begin{abstract}
The analysis of processes of gender oppression begins to emerge in philosophical reflections, either by focusing on the functioning of the patriarchal system or by focusing on the intersection of patriarchy with relations of domination from ethnic-racial origins. In general, such reflections seek to examine the foundations of oppressive systems and the reaction of women to such systems. Different forms and demands of feminist movements are found and the ways in which they seek, through the discussion of gender, to strengthen the social and political role of women. In this context, this article aims to examine the place of black feminism in the debate and its bases of support, in view of the peculiarities of the needs of black women. These peculiarities are related to the structural inseparability between patriarchy, sexism, racism, and its articulations that imply in multiple situations of oppression suffered by this group of women. In other words, it seeks to analyze the centrality of the concept of intersectionality for understanding the role of black feminism in philosophical reflections on the condition of black women in society.
\end{abstract}

Keywords: Black feminism - Gender - Intersectionality - Oppression - Race

\footnotetext{
${ }^{1}$ Halina Macedo Leal é professora de filosofia na Universidade Regional de Blumenau, FURB halina.leal@gmail.com.
} 


\section{Introdução}

Nas reflexões a respeito das questões de gênero, um dos pontos cruciais de análise diz respeito à ideia de natureza como definidora de categorias distintivas do masculino e do feminino. O sociólogo Pierre Bourdieu, no seu texto $A$ Dominação Masculina, aponta que "a divisão entre os sexos parece estar "na ordem das coisas" (...) para falar do que é normal, natural, a ponto de ser inevitável: ela está presente ao mesmo tempo, em estado objetivado nas coisas, em todo o mundo social e, em estado incorporado nos corpos e nos habitus dos agentes, funcionando como sistemas de esquemas de percepção, de pensamento e de ação. (...)"2 Segundo ele, esta naturalização dos corpos (em masculino e feminino) estabelece a divisão de atividades e funções que resultam em relações não simétricas entre os "sexos naturalizados". Nesta não simetria, o patriarcado se impõe por meio de modos de pensamento e de linguagem que se constituem como legítimos, objetivos e universais a partir dos quais situações de opressão sobre o denominado "gênero feminino" se manifestam de diferentes formas.

No que se refere às relações etnicorraciais, a perspectiva de construção social também surge, empreendida por pensadores que, tendo como base o exame do racismo e do colonialismo, refletem sobre a construção de condições de diferenciação e de dominação racial. Frantz Fanon, em Pele Negra, Máscaras Brancas, afirma que o racismo e o colonialismo devem ser compreendidos como modos socialmente construídos de apreender o mundo e viver nele. Para Fanon, não haveria necessidade de as pessoas pensarem sobre si mesmas em termos de raça se estas não se constituíssem subjetivamente a partir de uma linguagem que expressa significados de culturas e contextos sociais específicos que também são naturalizados. No que diz respeito ao racismo, a linguagem do colonizador é tida como a "verdadeira", carregando consigo o "verdadeiro significado" de como é a realidade e submetendo aqueles considerados "diferentes", os colonizados, neste caso os negros, a esta maneira de significação do mundo. Dito de outro modo, o negro passa a existir do outro para o outro, uma vez que é a partir da linguagem que ele passa a assumir uma cultura, que lhe é imposta, e a "suportar o peso de uma civilização" passa a ser negro, com todos os significados que o termo carrega numa perspectiva racista, a partir do momento em que o "colonizador/branco" o define como tal.

Tanto com respeito às questões de gênero quanto às questões etnicorraciais, há reações aos sistemas opressivos. No decorrer da história, são identificados movimentos de resistência - movimentos feministas e negros - que questionam não somente a naturalização das condições desiguais entre os grupos diversos da sociedade, mas a necessidade de superação das desigualdades, com reconhecimento de existência legítima de grupos oprimidos. Neste debate, quais seriam, então, as condições das mulheres negras cujos processos de opressão interseccionam questões de gênero e etnicorraciais?

Quando as opressões se interseccionam sobre as mulheres negras, as vivências da opressão se configuram em situações e necessidades peculiaridades deste grupo de mulheres. Nesta perspectiva, o feminismo negro surge com foco nestas peculiaridades, salientando que estas só podem ser apreendidas a partir da compreensão do lugar da mulher negra no

${ }^{2}$ BOURDIEU, A Dominação Masculina, p. 17.

${ }^{3}$ FANON, Pele Negra, Máscaras Brancas, p. 33. 
cruzamento interseccional das opressões de gênero e de raça e que, muitas vezes, resulta em opressão de classe.

O presente artigo busca, desta forma, analisar a centralidade do conceito de interseccionalidade para a compreensão das reflexões e ações do movimento feminista negro e de suas respostas às situações sociais vivenciadas pelas mulheres negras. Para tanto, o texto está dividido em três partes. $\mathrm{Na}$ primeira parte, se mostra a ausência de consideração das demandas das mulheres negras num histórico de momentos-chave dos movimentos feministas e, de forma pontual, em movimentos negros. Na segunda parte, é desenvolvida uma análise da interseccionalidade, conceitualmente cunhada pela jurista estadunidense Kimberlé Crenshaw (1959-), e que constitui a base de compreensão do feminismo negro. Na terceira parte, se busca mostrar que, a partir do reconhecimento da intersecção de opressões, o feminismo negro recusa o essencialismo, epistemologias universalistas e reivindica voz às mulheres negras a partir de seus lugares de fala.

\section{Feminismo, movimento negro e invisibilidade das mulheres negras}

Os questionamentos a respeito do lugar das mulheres negras nos debates feministas surgem na medida em que o histórico dos movimentos feministas indica desinteresse no tratamento de questões raciais. Angela Davis, em sua obra Mulheres, Raça e Classe ${ }^{4}$, descreve situações em que sufragistas estadunidenses se colocam ostensivamente contra o direito ao voto de homens negros, com argumentos voltados somente à questão de gênero, sem considerar os extremos que a condição de opressão de raça impunha às pessoas negras. Afirma Davis:

Havia um poderoso fator de ingenuidade política na análise feita por Stanton ${ }^{5}$ a respeito das condições vigentes no fim da guerra, o que significava que ela estava mais vulnerável do que nunca à ideologia racista. [...] Quando os republicanos ortodoxos contestaram a reivindicação pelo sufrágio feminino no pós-guerra com o slogan "Chegou a hora do negro", eles estavam, na verdade, dizendo em silêncio "Chegou a hora de mais de 2 milhões de votos para nosso partido". Contudo, Elizabeth Cady Stanton e suas seguidoras parecem ter acreditado que era "a hora do sexo masculino" e que os republicanos estavam dispostos a estender aos homens negros todos os privilégios da supremacia masculina. $\mathrm{Na}$ Convenção pela Igualdade de Direitos de 1867, quando foi questionada por um representante negro se apoiaria a extensão do voto aos homens negros mesmo que as mulheres não se tornassem eleitoras também, ela respondeu: "Digo que não; eu não confiaria a eles meus direitos; desvalorizados, oprimidos, eles poderiam ser mais despóticos do que nossos governantes anglo-saxões já são [...]”6.

\footnotetext{
${ }^{4}$ DAVIS, Mulheres, Raça e Classe, Capítulo 4.

${ }^{5}$ Elizabeth Cady Stanton foi uma sufragista que enviou uma carta ao editor do New York Standard, datada de 26 de dezembro de 1865, na qual expressa ideias racistas para justificar sua postura contra o direito ao voto para homens negros.

${ }^{6}$ DAVIS, Mulheres, Raça e Classe, pp. 82-83.
} 
Davis aponta que as sufragistas lideradas por Stanton expressaram total descontentamento quando, depois da Guerra Civil dos Estados Unidos, os homens negros obtiveram o direito ao voto e elas não, proferindo, naquele momento, reclamações explicitamente racistas. Este grupo de mulheres criticou emendas aprovadas em favor da concessão de direito ao voto aos homens negros da Associação pela Igualdade de Direitos:

(...) na defesa dos próprios interesses enquanto mulheres brancas de classe média, elas explicitavam - frequentemente de modo egoísta e elitista - seu relacionamento fraco e superficial com a campanha pela igualdade negra do pós-guerra. (...) Com a aprovação [do direito ao voto aos homens negros], elas sentiam possuir razões tão fortes a favor do sufrágio quanto os homens negros. No entanto, ao articular sua oposição com argumentos que evocavam os privilégios da supremacia branca, demonstravam o quanto permaneciam indefesas - mesmo após anos de envolvimento em causas progressistas contra a perniciosa influência ideológica do racismo. ${ }^{7}$

Neste movimento, além das feministas não conseguirem entrar num acordo em questões referentes à raça, nem cogitaram considerar a situação das mulheres negras. Estas foram totalmente ignoradas.

Posteriormente, saindo do contexto estadunidense, um outro grande movimento feminista ocorreu na França, tendo como base teórica a obra O Segundo Sexo (1949), de Simone de Beauvoir (1908-1986). Quando a Segunda Guerra Mundial (1939-1945) finda, a maioria dos países desenvolvidos e daqueles em que houve processos de descolonização, o voto das mulheres já era realidade. Com isto, muitas das demandas de movimentos feministas da época haviam sido satisfeitas e várias mulheres abandonaram a militância. Outras continuaram trabalhando, principalmente com os problemas econômicos e com as reformas das leis sobre a infância e a maternidade. Foi neste contexto, que a obra de Beauvoir inicia uma nova etapa do feminismo. Diferentemente de reivindicar direitos, como havia feito o feminismo até então, a filósofa discorre sobre a teoria de que a mulher historicamente tem sido considerada como a outra em relação ao homem, sem que haja reciprocidade. Ela salienta que o homem em nenhum momento é o outro, ao contrário ele é o centro, a medida e a autoridade. Neste sentido, o homem é o essencial e a mulher está sempre em relação de assimetria com ele. Com Beauvoir, o movimento feminista se assenta não somente nas reivindicações, mas nas indagações às ciências e disciplinas da cultura e do conhecimento, concluindo que não há nada de biológico nem de natural que explique a subordinação e a discriminação das mulheres. A cultura, segundo ela, se impõe e atribui papéis às mulheres.

Alguns anos depois, no contexto estadunidense, Betty Friedan, em sua obra $A$ Mística Feminina (1963), analisou a profunda insatisfação das mulheres estadunidenses consigo mesmas, com suas vidas e como elas traduziam essa insatisfação em problemas pessoais manifestados em diversas patologias como ansiedade e depressão, por exemplo. Para Friedan, para além de um problema particular, estas questões eram um problema político. A reação patriarcal contra o sufragismo, e a incorporação das mulheres na esfera pública durante a Segunda Guerra, fez com que a sociedade dominada por homens definisse o lugar

${ }^{7}$ DAVIS, Mulheres, Raça e Classe, pp. 84-85. 
da mulher como mãe e esposa, com possibilidades cerceadas de realização pessoal, sendo geralmente culpabilizada por não estar feliz:

O problema era minimizado dizendo à dona de casa que ela não percebia como tinha sorte: era sua própria chefe, não batia ponto, não tinha nenhum estagiário querendo roubar sua vaga. E daí que não fosse feliz? Ela achava que todo homem era feliz? Será que na verdade ainda desejava secretamente ser homem? Será que ainda não tinha se dado conta de como tinha sorte por ser mulher? (...) o problema também era minimizado quando se dizia que não havia solução: ser mulher é isso; o que há de errado com as estadunidenses que não conseguem aceitar seu papel com graciosidade?

Assim como as sufragistas, tanto Simone de Beauvoir quanto Betty Friedan não postularam a situação das mulheres negras. $\mathrm{O}$ fato é que, ao definirem indistintamente as questões de gênero, as feministas universalizaram as suas experiências e reduziram estas experiências às necessidades de um grupo de mulheres: das mulheres brancas de classe média.

Neste sentido, os movimentos feministas expressaram, em momentos-chave de seu desenvolvimento, um pensamento hegemônico reducionista, e, sobretudo, indiferente às situações de dominação e opressão sofridas pelas mulheres negras.

Sojourner Truth, no seu célebre discurso Não sou uma mulher?, proferido em 1851, na Convenção dos Direitos da Mulher em Akron, Ohio, já apontava para estas questões quando interrogava, em primeira pessoa, se a mulher negra não é mulher. Isto porque, enquanto força de trabalho, as mulheres negras sempre foram vistas como tão resistentes quanto qualquer homem. Num dos trechos de seu discurso, Truth afirma: “(...) eu poderia trabalhar tanto e comer tanto quanto qualquer homem - desde que eu tivesse oportunidade para isso - e suportar o açoite também! Não sou uma mulher? (...)". O que se observa, e Sojourner Truth foi pioneira em apontar isto, é que as mulheres negras nunca foram vistas como frágeis, como quem requer algum tipo de cuidado. Muito pelo contrário, suas imagens sempre estiveram associadas à disponibilidade para trabalhar, cuidar e servir, inclusive sexualmente. Estes pontos não eram contemplados nas reivindicações feministas. Em muitos casos, enquanto as feministas militavam e lutavam pelos seus direitos, as mulheres negras trabalhavam, cuidando da casa e dos filhos destas feministas.

No que se refere às questões de raça, as mulheres negras também não têm suas situações consideradas. Isto porque os movimentos negros, ao banirem debates e análises de gênero, vêm demonstrando desinteresse em combater o sexismo. Nestes movimentos, as questões raciais estão historicamente ocupando um lugar hierárquico superior às questões de gênero. Em geral, argumenta-se que, se as questões raciais forem resolvidas, automaticamente as dificuldades pelas quais as mulheres negras passam desapareceriam. Assim, negligencia-se o fato de que sobre as mulheres negras não recai somente a opressão racial. Por serem mulheres, recai também sobre elas a opressão de gênero e, de modos distintos e, por vezes, mais violentos do que sobre as mulheres brancas, já que as mulheres brancas não estão sujeitas ao racismo.

${ }^{8}$ FRIEDAN, A Mistica Feminina, p. 23. 
As feministas negras ressaltam que, neste contexto, as questões de raça e suas dificuldades associam-se unicamente ao ser homem negro, e as questões de gênero unicamente ao ser mulher branca. As experiências das mulheres negras não se inserem nem no ser mulher nem no ser negro. Seja nas discussões teóricas, seja nas vivências do dia a dia, a mulher negra experiencia o não lugar. Em Memórias da Plantação: episódios de racismo cotidiano, ao se referir a este ponto, Grada Kilomba afirma que as mulheres negras têm sido incluídas em diversos discursos que não interpretam as suas realidades. Segundo Kilomba, o sujeito do discurso de gênero é a mulher branca e o sujeito do discurso sobre o racismo é o homem negro. Deste não lugar ou - como afirma Kilomba, a partir de Heidi Safia Mirza (Black British Feminism, 1997) - deste espaço vazio que se sobrepõe às margens da raça e do gênero, denominado de "terceiro espaço", as mulheres negras habitam uma espécie de vácuo de apagamento e de contradição que se sustenta pela polarização entre mulheres de um lado e negros de outro, com as mulheres negras no meio. ${ }^{9}$ As mulheres brancas, embora sofram as consequências da opressão de gênero, numa sociedade racista, não sofrem a opressão de raça. Os homens negros, embora sofram as consequências do racismo, por serem homens numa sociedade patriarcal, não sofrem a opressão de gênero. Neste sentido, tanto homens negros quanto mulheres brancas encontram condições de se constituírem enquanto sujeitos. Com relação a este ponto, Grada Kilomba afirma:

As mulheres brancas têm um status oscilante, como o eu e como a "Outra" dos homens brancos porque elas são brancas, mas não homens. Os homens negros servem como oponentes para os homens brancos, bem como competidores em potencial por mulheres brancas, porque são homens, mas não são brancos. As mulheres negras, no entanto, não são brancas nem homens e servem, assim, como a "Outra" da alteridade. ${ }^{10}$

Kilomba ressalta que as narrativas separadas mantêm a invisibilidade das mulheres negras nos debates acadêmicos e políticos. ${ }^{11}$ Portanto, não é possível, no caso das mulheres negras, compreender gênero e opressão racial de forma separada, pois a separação aumenta a invisibilidade das diferentes necessidades das mulheres negras comparadas aos homens negros e às mulheres brancas.

\section{Feminismo negro e interseccionalidade}

É neste sentido que o feminismo negro tem como base a compreensão da noção de interseccionalidade. As opressões sofridas pelas mulheres negras são resultantes da intersecção de opressões de gênero e de raça e colocam a maioria das mulheres negras à margem do poder e da representação, invisibilizando-as em diferentes contextos.

Mesmo sem ser expresso conceitualmente, já com Sojourner Truth, no início do movimento, há uma primeira referência à interseccionalidade como uma provocação a se

\footnotetext{
${ }^{9}$ Cf. KILOMBA, Memórias da Plantação: episódios de racismo cotidiano, 2019.

${ }^{10}$ KILOMBA, Memórias da Plantação: episódios de racismo cotidiano, p. 191.

${ }^{11}$ KILOMBA, Memórias da Plantação: episódios de racismo cotidiano, pp. 97-98.
} 
pensar acerca das condições de opressão peculiares às mulheres negras. Mas foi somente a partir da década de 1960, em resposta ao sexismo do Movimento dos Direitos Civis dos negros nos EUA e ao racismo do movimento feminista, que o movimento de mulheres negras se tornou popular. Entre 1970 e 1980, formaram-se vários grupos que instigaram debates sobre o papel das mulheres negras nestes movimentos e em outros movimentos sociais, assumindo como base a interseccionalidade de opressões ${ }^{12}$.

A interseccionalidade é uma ferramenta teórica e metodológica utilizada pelas feministas negras para refletir acerca da inseparabilidade estrutural entre patriarcado, sexismo, racismo e suas articulações que implicam em múltiplas situações de opressão sofridas pelas mulheres negras. A intersecção de estruturas racistas e machistas sobre estas mulheres as coloca mais expostas a condições de vulnerabilidade política e social. Conceitualmente, o termo foi cunhado por Kimberlé Crenshaw (1959), jurista estadunidense, defensora dos direitos civis e professora de teoria crítica de raça, num contexto de crítica às leis antidiscriminação dos Estados Unidos.

Crenshaw, ao questionar o que há de errado com a visão tradicional das discriminações, afirma que um dos problemas é que as visões de discriminação racial e de gênero partem do princípio de que se fala de categorias diferentes de pessoas. A visão tradicional indica que a discriminação de gênero diz respeito às mulheres e a racial diz respeito à raça e à etnicidade. Assim como a discriminação de classe diz respeito apenas a pessoas pobres. Ela também aponta para outras categorias de discriminação (em função de deficiências, de idade, etc.) e ressalta que a interseccionalidade sugere que, na verdade, nem sempre lidamos com grupos distintos de pessoas e sim com grupos sobrepostos. Segundo ela, ao sobrepormos o grupo das mulheres com o das pessoas negras, o das pessoas pobres e o das mulheres que sofrem discriminação por conta da sua idade ou por serem portadoras de alguma deficiência, as mulheres de pele mais escura são as que tendem a ser as mais excluídas das práticas tradicionais de direitos civis e humanos. ${ }^{13}$ Para Crenshaw, a visão tradicional de discriminação opera no sentido de excluir as sobreposições.

Ela propõe, então, que pensemos em tipos de discriminação e em como isto opera com relação às mulheres negras. O primeiro tipo é a discriminação contra grupos específicos que, em última análise, se refere a mulheres que são interseccionais. A estas são associados estereótipos como, por exemplo, às mulheres da Bósnia e de Ruanda, onde a associação de etnicidade/raça como determinante de padrões sexuais gera situações de "violência justificada". Neste caso, a raça/etnia tende a conduzir a inferências e suposições a respeito de um grupo. O segundo tipo de discriminação, é a discriminação mista ou composta. Esta seria a combinação da discriminação racial e da discriminação de gênero. Neste caso, as mulheres negras são diretamente afetadas pela confluência das discriminações. E o terceiro tipo é a subordinação estrutural, quando não há qualquer discriminação ativa. O que ocorre

\footnotetext{
${ }^{12}$ Cabe ressaltar que, no Brasil, o feminismo negro ganha força e visibilidade a partir da década de 1970, com o Movimento de Mulheres Negras (MMN). Neste momento, pensadoras e ativistas negras problematizam a falta de uma abordagem interseccional nas pautas de gênero e de raça pelos movimentos sociais. De forma similar ao caminho analítico trilhado pelas feministas negras estadunidenses, as feministas negras brasileiras apontaram para a falta de abordagem racial no movimento feminista brasileiro, o qual não pautava a dupla discriminação sofrida pelas mulheres negras; assim como apontaram para a falta de interesse, no movimento negro liderado por homens, de atuar nas lutas contra o machismo e o sexismo.

${ }^{13}$ As referências de Crenshaw são com relação à situação das mulheres estadunidenses, mas pesquisas realizadas no Brasil indicam que a situação é similar. As mulheres negras, por exemplo, correspondem a $61 \%$ das vítimas de feminicídio no Brasil, de acordo com o Anuário Brasileiro de Segurança Pública de 2019.
} 
é que o peso combinado das estruturas de raça e das estruturas de gênero marginaliza as mulheres que estão na base e, geralmente, quem está na base é o grupo das mulheres negras. Tecnicamente, Crenshaw não atribui a denominação de discriminação a este tipo, ela denomina de subordinação, porque este não é voltado particularmente para grupos específicos. Não há um discriminador ativo. Em muitos casos, a subordinação não é resultante de políticas locais, mas de políticas internacionais e que têm efeito particular para as mulheres em decorrência da sua posição na estrutura socioeconômica. ${ }^{14}$ Crenshaw, exemplificando esta última denominação, diz:

O melhor exemplo da discriminação estrutural, talvez sejam as políticas de ajustes que muitos países são forçados a adotar. As feministas têm criticado as políticas de ajustes estruturais pelo efeito particular que elas têm sobre as mulheres. Geralmente, políticas de ajustes estruturais obrigam os países subalternos a desvalorizar suas moedas, o que, por sua vez, reduz salários e restringe serviços sociais, geralmente forçando as mulheres a assumirem serviços que deixam de ser prestados, como o de cuidar de idosos, doentes, jovens. (...) Em decorrência da sua boa condição socioeconômica, algumas mulheres (...) conseguem contratar a mão-de-obra de outras mulheres para assumirem esses serviços de cuidados. As contratadas, em geral, são mulheres economicamente marginalizadas, que, por essa razão, são também socialmente marginalizadas, situadas na base da pirâmide socioeconômica. (...) É isso que eu chamo de subordinação estrutural, a confluência entre gênero, classe, globalização e raça. ${ }^{15}$

O conceito de interseccionalidade denota, assim, as diferentes maneiras pelas quais raça e gênero interagem para moldar as várias experiências pelas quais as mulheres negras são submetidas. Estas experiências não são compreendidas se não for considerado o modo como a intersecção do racismo e do sexismo afeta estas mulheres, moldando aspectos estruturais, políticos, representacionais que geram violências e as colocam na base da sociedade.

Crenshaw ressalta, ainda, que a interseccionalidade não é uma teoria totalizante da identidade. O foco é destacar a necessidade de explicar os múltiplos aspectos da identidade, ao considerar como a realidade social é construída.

Segundo Carla Akotirene, em O que é interseccionalidade?, este conceito "é uma sensibilidade analítica, pensada por feministas negras"16. Em outras palavras, este é um conceito que deve ser interpretado, no âmbito do feminismo negro, com base em variáveis implicadas nos debates aí empreendidos.

\footnotetext{
${ }^{14}$ CRENSHAW, “A Interseccionalidade na discriminação de raça e gênero”, 2002.

${ }^{15}$ CRENSHAW, "A interseccionalidade na discriminação de raça e gênero", pp. 13-14.

${ }^{16}$ AKOTIRENE, O que é interseccionalidade?, p. 13.
} 


\section{Epistemologias e vozes}

A partir do conceito de interseccionalidade, compreende-se o fato de as feministas negras articularem o feminismo negro como um movimento não essencialista e que questiona as epistemologias universalistas. Se apreende o não essencialismo do movimento, na medida em que a compreensão da situação das mulheres negras passa pela compreensão da sobreposição de opressões estabelecidas socialmente. Não há uma "natureza" e nem a possibilidade de se recorrer a "essências" para justificar o que ocorre; tudo depende de interações e articulações sociais em que grupos são definidos de determinada forma, em função de interesses de domínio e hegemonia. No que se refere à crítica a epistemologias universalistas, os argumentos caminham na mesma direção da crítica do filósofo da ciência Paul Feyerabend (1924-1994) à ideia de um universalismo na ciência e na linguagem científica:

(...) A unanimidade de opinião pode servir a uma igreja, às vítimas aterradas ou ávidas de um (antigo ou moderno) mito, ou aos seguidores fracos e voluntários de um tirano. A variedade de opiniões é necessária ao conhecimento objetivo. E um método que encoraje a variedade é também o único método compatível com uma perspectiva de humanidade. (... $)^{17}$

Feyerabend critica o universalismo na ciência e a imposição deste modo de conhecer na sociedade. Há aí a crítica à imposição de um conhecimento universal que reflete os interesses específicos de um grupo dominante. Na obra, A Ciência em uma Sociedade Livre, ele rechaça a ideia de dominação que subjaz ao universalismo:

"Igualdade", incluindo a igualdade da mulher e a igualdade racial, não significa igualdade das tradições, mas apenas a igualdade de acesso a uma tradição particular: a tradição do homem branco. Os liberais brancos, que apoiam a busca da igualdade com todas as suas forças, abriram a terra prometida, mas uma terra prometida que se deve construir segundo os seus planos, que deve encher-se dos seus brinquedos favoritos e em que só se pode entrar com a sua autorização. ${ }^{18}$

A epistemologia não diz respeito somente a conhecimento, mas a quem produz o conhecimento considerado válido ou verdadeiro. Neste sentido, a epistemologia, ou como Feyerabend cita, a "tradição do homem branco" impede o conhecimento de diferentes perspectivas e desconsidera outros saberes como, por exemplo, de povos originários e grupos subalternizados. Em última análise, a ideia de um conhecimento universal, além de expressar interesses específicos de um grupo social dominante, impede o conhecimento de diferentes perspectivas, desconsiderando saberes de outras e outros sujeitos colocados à margem do conhecimento estabelecido.

O pensamento das feministas negras vai ao encontro do que Feyerabend expõe. $\mathrm{O}$ feminismo negro, indo de encontro ao universalismo, busca desenvolver e identificar

${ }^{17}$ FEYERABEND, Against Method, pp. 31-32

${ }^{18}$ FEYERABEND, A Ciência em uma Sociedade Livre, p. 95. 
variadas narrativas, validando conhecimentos e discursos para além dos discursos hegemônicos eurocêntricos. A ideia de epistemologia do movimento feminista negro envolve a valorização das experiências de vida e de visões de mundo das mulheres afrodescendentes.

No livro Pensamento Feminista Negro: conbecimento, consciência e a politica do empoderamento (1990), Patrícia Hill Collins ${ }^{19}$ aponta para quatro dimensões da epistemologia feminista negra. A primeira dimensão é a da valorização da sabedoria, envolvendo a perspectiva vivencial; a segunda é a do diálogo com outros membros da comunidade, para além do âmbito acadêmico, vistos como importantes para a construção de novos conhecimentos. A terceira dimensão é a da ética do cuidado, na qual fatores como a expressividade pessoal, as emoções e a empatia são considerados como fundamentais no processo de validação do conhecimento; e, finalmente, a ética da responsabilidade pessoal, a partir da qual espera-se que o indivíduo tenha relação direta com suas próprias ideias e se responsabilize pelo seu discurso ${ }^{20}$.

Neste sentido, a epistemologia do feminismo negro ressalta a interação entre teoria e vivência, a centralidade analítica das experiências e ideias das mulheres negras, a criatividade intelectual e a exigência de que o pensamento implique ações, assim como ações impliquem pensamentos. Tudo isto considerando uma linguagem que abarque não somente a objetividade, mas a subjetividade em discursos considerados válidos. Este último ponto ressalta a necessidade de, no contexto epistemológico, não se desvincular a narrativa da pessoa que narra. Esta deve ter consciência do seu lugar no discurso, revelando, para si e para os outros, o lugar social do qual fala. É nesta direção que o conceito de "lugar de fala" se apresenta também como constituinte do feminismo negro.

Djamila Ribeiro, em O que é lugar de fala? (2017), explica que o conceito de "lugar de fala" reivindica diferentes pontos de análises e diferentes afirmações, buscando refutar a historiografia tradicional e a hierarquização dos saberes. O conceito serve para auxiliar na compreensão de como as falas marcam relações de poder e eventualmente reproduzem preconceitos e estereótipos. "Lugar de fala" não é somente o poder falar. O conceito não pretende apenas legitimar a expressão de um amontoado qualquer de palavras, mas revelar uma hierarquia violenta que subjaz as autorizações e as decisões sobre quem pode e quem não pode falar. Essa hierarquia, por sua vez, é fruto da classificação racial, de gênero e de classe de grupos de pessoas.

O "Lugar de fala" surge para problematizar e refutar alguns pressupostos da epistemologia dominante, na medida em que possibilita trazer à consciência a existência de estruturas única e essencialmente relacionadas à branquitude no discurso dominante, sob um olhar branco, masculino e europeu. A partir da tomada de consciência que o uso do conceito permite, ele se configura como possibilidade eficaz de enfrentamento do discurso dominante, por meio da promoção da multiplicidade de vozes. Estas vozes apresentam-se como potencialmente capazes de quebrar o discurso autorizado e que se pretende universal. Segundo Ribeiro, "lugar de fala":

\footnotetext{
19 Collins compreende que, mesmo que focada no contexto estadunidense, sua perspectiva abarca outras experiências de mulheres negras na diáspora. Assim, ela tenta explicar as dimensões do conceito de epistemologia que sustenta o movimento.

${ }^{20}$ Cf. COLLINS, Pensamento Feminista Negro: conbecimento, consciência e a politica do empoderamento, 2019.
} 
[...] representa o fim da mediação na fala, ou seja, representa o sujeito como protagonista de seu próprio discurso reivindicatório. [...] [discurso] como um sistema que estrutura determinado imaginário social, [no qual se fala, portanto, de poder e controle] [...] O falar, neste caso, não se restringe ao ato de emitir palavras, mas de poder existir. ${ }^{21}$

"Lugar de fala" expressa o existir em si, para si, enquanto sujeito, no seu lugar social. Neste sentido, todos temos um lugar de fala, pois somos atravessados pelo lugar social que ocupamos. Todos podemos e devemos falar de tudo, a partir da consciência de nosso lugar social. No feminismo negro, a importância de considerar o "lugar de fala" é que este nos permite, primeiramente, identificar qual é o discurso autorizado. Num segundo momento, situar os discursos e, num terceiro movimento, para além de "falar", convocar os sujeitos à escuta. É importante escutar as "vozes dissonantes" do discurso autorizado, ou melhor, escutar as vozes do discurso "não autorizado", pois estas já foram silenciadas durante muito tempo. O objetivo não é calar as vozes do discurso que até então se assumiu como válido, mas situá-las, observando a emergência de distintas narrativas por meio de distintas vozes. A linguagem se configura, assim, em caminho de empoderamento e ação.

O objetivo do feminismo negro é o desenvolvimento do empoderamento das mulheres negras, a partir de si mesmas, de discursos próprios, tendo em vista o que Collins denomina de justiça social ou o que Davis salienta como modificação das estruturas sociais. Este empoderamento não é direcionado pura e simplesmente para conquistas individuais, mas às coletividades de mulheres negras que desenvolvem um entendimento de sua condição social e política, de sua história e de suas variadas habilidades, autoafirmando-se e trilhando caminhos de superação das condições impostas pela dominação. Nesse sentido, a superação não envolve somente a libertação das mulheres negras individualmente ou enquanto grupo, mas envolve também a libertação de homens negros, mulheres não negras, comunidade lgbtqia + e todas e todos em situações de desigualdade e opressão. Em última análise, ao refletir sobre as bases dos sistemas opressivos, o feminismo negro amplia e diversifica não somente o debate, mas seu campo de atuação enquanto um movimento social e político.

\section{Considerações finais}

No presente artigo, buscou-se mostrar que, em momentos-chave de movimentos feministas e movimentos negros, as demandas das mulheres negras não foram, e muitas vezes ainda não são, consideradas. Avaliar os problemas das mulheres negras somente sob o ponto de vista de uma questão de gênero ou somente como uma questão de raça produz e reproduz "não lugares" sociais a este grupo de mulheres.

Neste sentido, o feminismo negro surge como um movimento que, partindo de condições de invisibilização impostas às mulheres negras, assume como base de compreensão da situação destas mulheres o conceito de interseccionalidade de opressões que recai sobre elas. Este movimento, ao assumir como base argumentativa o cruzamento interseccional, amplia o olhar sobre as questões de gênero e raciais e permite a construção e

${ }^{21}$ RIBEIRO, O que é lugar de fala?, p. 56 e p. 64. 
a proposição de alternativas aos problemas aí identificados. Estas alternativas direcionam-se não somente a questões práticas, de condições de vida e sobrevivência destas mulheres, mas a questões epistemológicas referentes ao conhecimento considerado válido e o quanto a imposição de saberes serve a discursos e narrativas de dominação e silenciamento de vozes.

\section{Referências bibliográficas}

AKOTIRENE, Carla. O que é interseccionalidade? Belo Horizonte, MG: Letramento: Justificando, 2018.

BOURDIEU, Pierre. A Dominação Masculina. Rio de Janeiro: Bertrand Brasil, 2012.

COLLINS, Patrícia Hill. Pensamento Feminista Negro: conbecimento, consciência e a política do empoderamento. tradução Jamile Pinheiro Dias. 1 ed. São Paulo: Boitempo, 2019.

CRENSHAW, Kimberlé. A Interseccionalidade na Discriminação de Raça e Gênero. Cruz̧amento: Raça e gênero. Brasília, p. 7-16, 2004.

DAVIS, Angela. Mulheres, Raça e Classe. Tradução Heci Regina Candiani. 1 ed. São Paulo: Boitempo, 2016.

FANON, Frantz. Pele Negra, Máscaras Brancas. Salvador: EDUFBA, 2008.

FEYERABEND, Paul. Against Method. Londo: Verso, 1993. A Ciência em uma Sociedade Livre. São Paulo: UNESP, 2011.

FRIEDAN, Betty. A Mistica Feminina. 1ª Edição. Rio de Janeiro: Rosa dos Tempos, 2020.

HOOKS, bell. E eu não sou uma mulher? Mulheres negras e feminismo. Tradução Bhuvi Libanio. 1 ed. Rio de Janeiro: Rosa dos Tempos, 2019.

Teoria Feminista: da margem ao centro. Tradução Rainer Patriota. - São Paulo: Perspectiva, 2019.

JORDAN, June. Civil Wars. Boston: Beacon Press, 1981.

KILOMBA, Grada. Memórias da Plantação: episódios de racismo cotidiano. Tradução Jess Oliveira. 1 ed. Rio de Janeiro: Cobogó, 2019.

LORDE, Audre. Sister Outsider. Berkeley: Crossing Press, 2007.

RIBEIRO, Djamila. O que é lugar de fala?. Belo Horizonte: Letramento: Justificando, 2017. 